\title{
Approaches to Delivery of Care at Home Following Elective Hip and Knee Joint Replacement Surgery
}

\author{
M. Alnaib, N. R. Agni, N. Shaw \\ University Hospital of North Durham, Durham, UK \\ Email: Nickil.Agni@googlemail.com, Alnaib@gmail.com
}

Received 3 July 2015; accepted 28 July 2015; published 31 July 2015

Copyright (C) 2015 by authors and Scientific Research Publishing Inc.

This work is licensed under the Creative Commons Attribution International License (CC BY).

http://creativecommons.org/licenses/by/4.0/

(c) () Open Access

\begin{abstract}
Arthritis has a worldwide increasing prevalence with increased demands on healthcare systems to provide arthroplasty surgery. There is growing evidence that early discharge and rehabilitation at home following hip and knee replacement provide similar or better results in function, complication rates and patient satisfaction. We suggest that this method of rehabilitation is a cost-effective viable option in fitter patients whose medical demands will be low postoperatively.
\end{abstract}

\section{Keywords}

\section{Rehabilitation, Arthroplasty, Arthritis}

\section{Introduction}

Arthritis of the hip and knee remains a leading cause of disability among patients and the number of patients diagnosed with arthritis continues to grow. This increasing prevalence places overwhelming demand on global health care systems for joint arthroplasty surgery [1]. In addition to this, the contribution of other factors including increasing life expectancy, obesity and patient desires to maintain a pain free active lifestyle further increases this pressure [2]-[4].

In their analysis of the incidence of total hip replacement for primary osteoarthritis in Iceland, Ingvarsson et al. (1999) have shown that the annual requirement for this procedure is expected to increase by one-third over a period of twenty years [5]. Mallinson et al. (2011) have shown even higher prevalence for hip and knee replacement surgery in the United States [6]. The factors above have resulted in methods of cost saving strategies whilst maintaining high quality patient care. The development of clinical pathways is an attempt to standardize management and to better economize with available resources [7]. 
Clinical pathways have been used since the 1980's, and over the last 3 decades there has been increasing debate regarding their effect on patients' outcomes and care. In their meta-analysis of clinical pathways in joint replacement surgery, Barbieri et al. (2009) have found that clinical pathways can improve perioperative care quality and significantly decrease the incidence of postoperative complications [1].

Most joint arthroplasty patients will require some form of rehabilitation whether in hospital, at home or in a specialist rehabilitation centre. This review will look in the evidence for delivering rehabilitation at home.

\section{Rehabilitation at Home Following Surgery}

An important part in the setup of any perioperative clinical pathway is to decide whether patients' should have their care and rehabilitation delivered at home, in outpatient facilities or in hospital. Historically, patient who underwent joint replacement surgery have been managed routinely in hospitals. Over the last three decades, there has been an increasing drive to manage those patients at home and is no longer compulsory to rehabilitate those patients in hospital [8]. The incentives behind this drive include clinical, financial, resource availability and evidence in the literature.

There are many studies showing that functional capacity and patient satisfaction are good following home therapy, with similar or better outcome and complication rates when compared to hospital rehabilitation programmes [9]-[12]. In a comparative study of functional outcome following joint replacement in patients who received rehabilitation at home, outpatients or hospital, home rehabilitation was found to be the optimal setting for healthy, less dependent patients and offered a significant advantage in recovery of functional status [6]. Many authors also show an enhanced patient satisfaction mainly due to shorter inpatient stays resulting in an increased ability to cope following arthroplasty [13]-[15]. Functionally, a randomized study by Siggeirsdottir (2005) has shown statistically significant better Oxford hip scores in patients who had perioperative education and home rehabilitation [16].

\subsection{Education}

Perioperative education has shown to play an important role in the ability of patients to manage at home following surgery, in addition to improved function and quality of life, when associated with post-operative home rehabilitation programmes (GENET 2007) [8]. Wang (2002) have found that the introduction of an education programme resulted in improved quality of gait and endurance at 6 months [17]. There was also reduction in hospital length of stay when combined with rehearsal of postoperative exercises resulting in cost savings, which has been supported by other studies in current literature [16]-[18]. Furthermore, the assessment of patient's home and family environment by nurses and physiotherapists before surgery increased patient satisfaction and lightened postoperative management [10]. A qualitative study by Delmar (2009) has shown that describing rehabilitation to patients in a personal way, especially for the elderly, as a process linked to being at home and achieving harmony with one's self was more valid rather than simply providing standardized information irrelevant to patients' personal needs [19].

Conversely, there is evidence to support inpatient, and to some extent specialised outpatient, rehabilitation following joint replacement surgery. DeJong (2009) have found better outcomes in patients receiving inpatient rehabilitation when compared to those who had outpatient rehabilitation in skilled-nursing facilities [20]. They showed that for sicker patients undergoing arthroplasty, the availability of 24-hour medical and nursing care was needed when compared to healthy patients. Genet (2007) have found that some physiotherapy techniques will require the presence of specialist physiotherapists, particularly in managing cardiorespiratory deconditioning and suggested for this element to be added to rehabilitation programmes [8].

\subsection{Cost}

Reducing cost has been, and will always be, an important drive in early discharge. Moller (1992) has found that it was feasible to transfer patients' rehabilitation home following arthroplasty [21]. Most authors agree that the main contributor to cost reduction is reduced length of stay [14] [16] [22]. Sigurdsson (2008) achieved a cost reduction of $28 \%$ in their randomised trial comparing early discharge following total hip replacement when compared to discharge to a rehabilitation centre [7]. They concluded that shorter length of stay is cost-efficient requiring fewer resources and potentially results in shorter waiting times to have surgery. The introduction of 
clinical pathways has also contributed to the reduced length of stay due to standardization of management and better organization [1]. Kim (2003) has also shown that clinical pathways reduced length of stay by $31 \%$ achieving a cost reduction of $11 \%$ for total hip replacements [23].

There is increasing evidence that early discharge to home physiotherapy may have the intention of reducing cost and readmission rates but in reality this is not the case. Coyte (2000) demonstrated that patients discharged with home care had longer acute care stays than other patients [24]. The provision of home care services increased health system costs, and acute care readmission rates were greatest among patients discharged with home care. Mitchell (2005) carried out a randomised control trial of home versus hospital rehabilitation after unilateral TKR [25]. They showed that home rehabilitation resulted no difference in outcome but there were significantly more physiotherapy sessions for the home group resulting in an excess mean cost of £136.5 per patient.

Genet (2007) have described the evidence in the literature as heterogeneous when it comes to assessing outcome measures and home therapy regimes, with lack of consensus on rehabilitation strategies [8]. Barbieri (2009) could not conclude that clinical pathways in general were cost-effective due to the lack of studies analysing the cost of development of those pathways [1]. Other studies have also shown no significant difference between hospital and outpatient rehabilitation programmes following hip and knee arthroplasty thus showing the controversy in current literature [6] [9] [26].

\section{Conclusions}

Current literature shows that there is no real consensus regarding the outcomes from delivery of rehabilitation in alternative settings. There is growing evidence that early discharge and rehabilitation at home following hip and knee replacement provide similar or better results in function, complication rates and patient satisfaction. We suggest that this method of rehabilitation is a cost-effective viable option in fitter patients whose medical demands will be low postoperatively.

There is a lack of good randomised control trials comparing home and hospital rehabilitation in the literature. A well constructed trial looking at functional outcome and patient satisfaction following THR and TKR would be beneficial.

\section{References}

[1] Barbieri, A., Vanhaecht, K., Van Herck, P., Sermeus, W., Faggiano, F., Marchisio, S. and Panella, M. (2009) Effects of Clinical Pathways in the Joint Replacement: A Meta-Analysis. Biomedcentral Medicine, 7, 32. http://dx.doi.org/10.1186/1741-7015-7-32

[2] Lavernia, C.J., D’apuzzo, M.R., Hernandez, V.H., Lee, D.J. and Rossi, M.D. (2006) Postdischarge Costs in Arthroplasty Surgery. Journal of Arthroplasty, 21, 144-150. http://dx.doi.org/10.1016/j.arth.2006.05.003

[3] Kurtz, S., Mowat, F., Ong, K., Chan, N., Lau, E. and Halpern, M. (2005) Prevalence of Primary and Revision Total Hip and Knee Arthroplasty in the United States from 1990 through 2002. Journal of Bone and Joint Surgery America, 87, 1487-1497. http://dx.doi.org/10.2106/JBJS.D.02441

[4] Vasarhelyi, E.M. and Macdonald, S.J. (2012) The Influence of Obesity on Total Joint Arthroplasty. Journal of Bone and Joint Surgery Britain, 94-B, 100-102. http://dx.doi.org/10.1302/0301-620X.94B11.30619

[5] Ingvarsson, T., Hagglund, G., Jonsson, H. and Lohmander, L.S. (1999) Incidence of Total Hip Replacement for Primary Osteoarthrosis in Iceland 1982-1996. Acta Orthopaedica Scandinavica, 70, 229-233. http://dx.doi.org/10.3109/17453679908997798

[6] Mallinson, T.R., Bateman, J., Tseng, H.Y., Manheim, L., Almagor, O., Deutsch, A. and Heinemann, A.W. (2011) A Comparison of Discharge Functional Status after Rehabilitation in Skilled Nursing, Home Health, and Medical Rehabilitation Settings for Patients after Lower-Extremity Joint Replacement Surgery. Archives of Physical Medicine and Rehabilitation, 92, 712-720. http://dx.doi.org/10.1016/j.apmr.2010.12.007

[7] Sigurdsson, E., Siggeirsdottir, K., Jonsson, H., Gudnason, V., Matthiasson, T. and Jonsson, B.Y. (2008) Early Discharge and Home Intervention Reduces Unit Costs after Total Hip Replacement: Results of a Cost Analysis in a Randomized Study. International Journal of Health Care Finance and Economics, 8, 181-192. http://dx.doi.org/10.1007/s10754-008-9036-0

[8] Genet, F., Mascard, E., Coudeyre, E., Revel, M. and Rannou, F. (2007) The Benefits of Ambulatory Physiotherapy after Total Knee Replacement. Clinical Practice Recommendations. Annales de Réadaptation et de Médecine Physique, 50, 793-801, 783-792. 
[9] Shepperd, S. and Iliffe, S. (2005) Hospital at Home versus In-Patient Hospital Care. Cochrane Database of Systematic Reviews, CD000356. http://dx.doi.org/10.1002/14651858.cd000356.pub2

[10] Weaver, F.M., Hughes, S.L., Almagor, O., Wixson, R., Manheim, L., Fulton, B. and Singer, R. (2003) Comparison of Two Home Care Protocols for Total Joint Replacement. Journal of the American Geriatrics Society, 51, 523-528. http://dx.doi.org/10.1046/j.1532-5415.2003.51162.x

[11] Mahomed, N.N., Koo Seen Lin, M.J., Levesque, J., Lan, S. and Bogoch, E.R. (2000) Determinants and Outcomes of Inpatient versus Home Based Rehabilitation Following Elective Hip and Knee Replacement. The Journal of Rheumatology, 27, 1753-1758.

[12] Crotty, M., Whitehead, C., Miller, M. and Gray, S. (2003) Patient and Caregiver Outcomes 12 Months after HomeBased Therapy for Hip Fracture: A Randomized Controlled Trial. Archives of Physical Medicine and Rehabilitation, 84, 1237-1239. http://dx.doi.org/10.1016/S0003-9993(03)00141-2

[13] Gammon, J. and Mulholland, C.W. (1996) Effect of Preparatory Information Prior to Elective Total Hip Replacement on Post-Operative Physical Coping Outcomes. International Journal of Nursing Studies, 33, 589-604. http://dx.doi.org/10.1016/S0020-7489(96)00019-3

[14] Parker, M.J., Pryor, G.A. and Myles, J.W. (1991) Early Discharge after Hip Fracture. Prospective 3-Year Study of 645 Patients. Acta Orthopaedica, 62, 563-556. http://dx.doi.org/10.3109/17453679108994497

[15] Sikorski, J.M. and Senior, J. (1993) The Domiciliary Rehabilitation and Support Program: Rationale, Organization, and Outcome. Medical Journal of Australia, 159, 23-25.

[16] Siggeirsdottir, K., Olafsson, O., Jonsson, H., Iwarsson, S., Gudnason, V. and Jonsson, B.Y. (2005) Short Hospital Stay Augmented with Education and Home-Based Rehabilitation Improves Function and Quality of Life after Hip Replacement: Randomized Study of 50 Patients with 6 Months of Follow-Up. Acta Orthopaedica, 76, 555-562. http://dx.doi.org/10.1080/17453670510041565

[17] Wang, A.W., Gilbey, H.J. and Ackland, T.R. (2002) Perioperative Exercise Programs Improve Early Return of Ambulatory Function after Total Hip Arthroplasty: A Randomized, Controlled Trial. American Journal of Physical Medicine \& Rehabilitation, 81, 801-806. http://dx.doi.org/10.1097/00002060-200211000-00001

[18] Jones, S., Alnaib, M., Kokkinakis, M., Wilkinson, M., St Clair Gibson, A. and Kader, D. (2011) Pre-Operative Patient Education Reduces Length of Stay after Knee Joint Arthroplasty. Annals of the Royal College of Surgeons of England, 93, 71-75.

[19] Delmar, C., Rasmussen, B. and Dolmer, I. (2009) Staying in the Stream of Life: Rehabilitation of Older People in Their Own Homes Following Total Hip Replacement. International Journal of Older People Nursing, 4, $272-279$. http://dx.doi.org/10.1111/j.1748-3743.2009.00174.x

[20] Dejong, G., Hsieh, C.H., Gassaway, J., Horn, S.D., Smout, R.J., Putman, K., James, R., Brown, M., Newman, E.M. and Foley, M.P. (2009) Characterizing Rehabilitation Services for Patients with Knee and Hip Replacement in Skilled Nursing Facilities and Inpatient Rehabilitation Facilities. Archives of Physical Medicine and Rehabilitation, 90, 12691283.

[21] Moller, G., Goldie, I. and Jonsson, E. (1992) Hospital Care versus Home Care for Rehabilitation after Hip Replacement. International Journal of Technology Assessment in Health Care, 8, 93-101. http://dx.doi.org/10.1017/S0266462300007959

[22] Kenney, G.M. and Dubay, L.C. (1992) Explaining Area Variation in the Use of Medicare Home Health Services. Medical Care, 30, 43-57. http://dx.doi.org/10.1097/00005650-199201000-00004

[23] Kim, S., Losina, E., Solomon, D.H., Wright, J. and Katz, J.N. (2003) Effectiveness of Clinical Pathways for Total Knee and Total Hip Arthroplasty: Literature Review. The Journal of Arthroplasty, 18, 69-74. http://dx.doi.org/10.1054/arth.2003.50030

[24] Coyte, P.C., Young, W. and Croxford, R. (2000) Costs and Outcomes Associated with Alternative Discharge Strategies Following Joint Replacement Surgery: Analysis of an Observational Study Using a Propensity Score. Journal of Health Economics, 19, 907-929. http://dx.doi.org/10.1016/S0167-6296(00)00041-2

[25] Mitchel, C., Walker, J., Walters, S., et al. (2005) Costs and Effectiveness of Pre- and Post-Operative Home Physiotherapy for Total Knee Replacement: Randomized Controlled Trial. Journal of Evaluation in Clinical Practice, 11, 283-292.

[26] Kramer, J.F., Speechley, M., Bourne, R., Rorabeck, C. and Vaz, M. (2003) Comparison of Clinic- and Home-Based Rehabilitation Programs after Total Knee Arthroplasty. Clinical Orthopaedics and Related Research, 410, 225-234. http://dx.doi.org/10.1097/01.blo.0000063600.67412.11 